\title{
Museu do Futebol: - Brasil com emoção, história e diversão
}

Laura Avancine

Jornalista, assessora de imprensa da Approach Gestão de Informação.

E-mail: laura.avancine@approach.com.br

Resumo: localizado no Estádio do Pacaembu, em São Paulo (SP), o Museu do Futebol é um museu típico do terceiro milênio e propõe uma narrativa linear, obtida com o uso de multimeios. A história do futebol é contada com base nos eixos de emoção, história e diversão. A curadoria de Leonel Kaz revela uma sequência de experiências visuais e sonoras que relacionam o esporte e a vida brasileira no século XX. Os conteúdos são comunicados ao público sob a forma de exposições, palestras, cursos, oficinas, eventos, publicações, ações educativas intra e extramuros.

Palavras-chave: futebol, história, museu, memória, educação.
Abstract: placed in Estadio do Pacaembu, in Sao Paulo (SP), the Museu do Futebol is a typical third millennium museum and proposes to make a linear narrative with the use of multimedia. History of soccer is told through the axes Emotion, History and Fun. The curatorship of Leonel Kaz reveals a sequence of visual and sound experiences that set the relationship between soccer and Brazilian life in the 20th century. Contents are communicated to the audience under the shape o expositions, addresses, courses, workshops, functions, publications, inside and outside educative activities.

Keywords: soccer, history, museum, memory, education.

O Museu do Futebol é um museu da história do Brasil. Uma história que tornou o futebol uma das mais reconhecidas manifestações culturais do País. O povo brasileiro se apropriou do futebol, apaixonadamente. No Museu vamos entender como esse esporte, de origem inglesa, da elite e branco, aos poucos ganhou novos traços: tornou-se brasileiro, popular e mestiço e transformou-se num espelho da nossa cultura.

Foi inaugurado no dia 29 de setembro, no Estádio do Pacaembu, localizado em frente à Praça Charles Miller, em São Paulo. Palco de diversas comemorações de títulos e fatos históricos, como o gol "de bicicleta" de Leônidas da Silva, o Pacaembu tornou-se ideal para sediar o Museu do Futebol. Espaço dedicado à celebração desse esporte, o Museu vai mostrar - a partir dos três eixos que norteiam a visita: emoção, história e diversão - o que Leônidas da Silva tem a ver com Villa-Lobos, Jorge Amado e Candido Portinari. E até mesmo como a trágica derrota da Copa de 1950 ajudou o Brasil a reinventar o seu futebol e ser o maior vencedor de copas mundiais. 
comunicação \& educação • Ano XIV • Número 3 • set/dez 2009

Ocupa uma área de $6.900 \mathrm{~m}^{2}$ no avesso das arquibancadas, na entrada principal de um dos mais bonitos estádios brasileiros, o Estádio Municipal Paulo Machado de Carvalho - mais conhecido como Estádio do Pacaembu. Orçado em R\$ 32,5 milhões, o Museu é uma iniciativa do Governo do Estado e da Prefeitura de São Paulo - por meio da Secretaria Municipal de Esportes e da São Paulo Turismo -, com concepção e realização da Fundação Roberto Marinho, em parceria com Santander, Telefônica, Ambev, Visa e Rede Globo. O projeto também conta com o apoio da Samsung, da Epson, do SporTV, da Carrier, da Otis e da Lei de Incentivo à Cultura do Ministério da Cultura, e com a colaboração da Confederação Brasileira de Futebol (CBF). O Museu também fará parte da rede estadual de museus de São Paulo.

\section{O MUSEU}

Visitar o Museu do Futebol é percorrer a história brasileira no século XX e perceber como nossos usos, costumes e comportamentos ilustram esta narrativa. O futebol ajudou a formar a identidade brasileira, assim como a cultura brasileira ajudou a transformar o futebol. Os craques que o Brasil foi capaz de criar representam tanto a nossa cultura quanto os ícones das artes plásticas, da literatura, do teatro, da música. E o Museu do Futebol chega para consagrar, definitivamente, o futebol como cultura viva, inventiva e emocionante.

O detalhado projeto de concepção do Museu do Futebol foi fundamentado em três pilares: arquitetura, conteúdo e museografia.

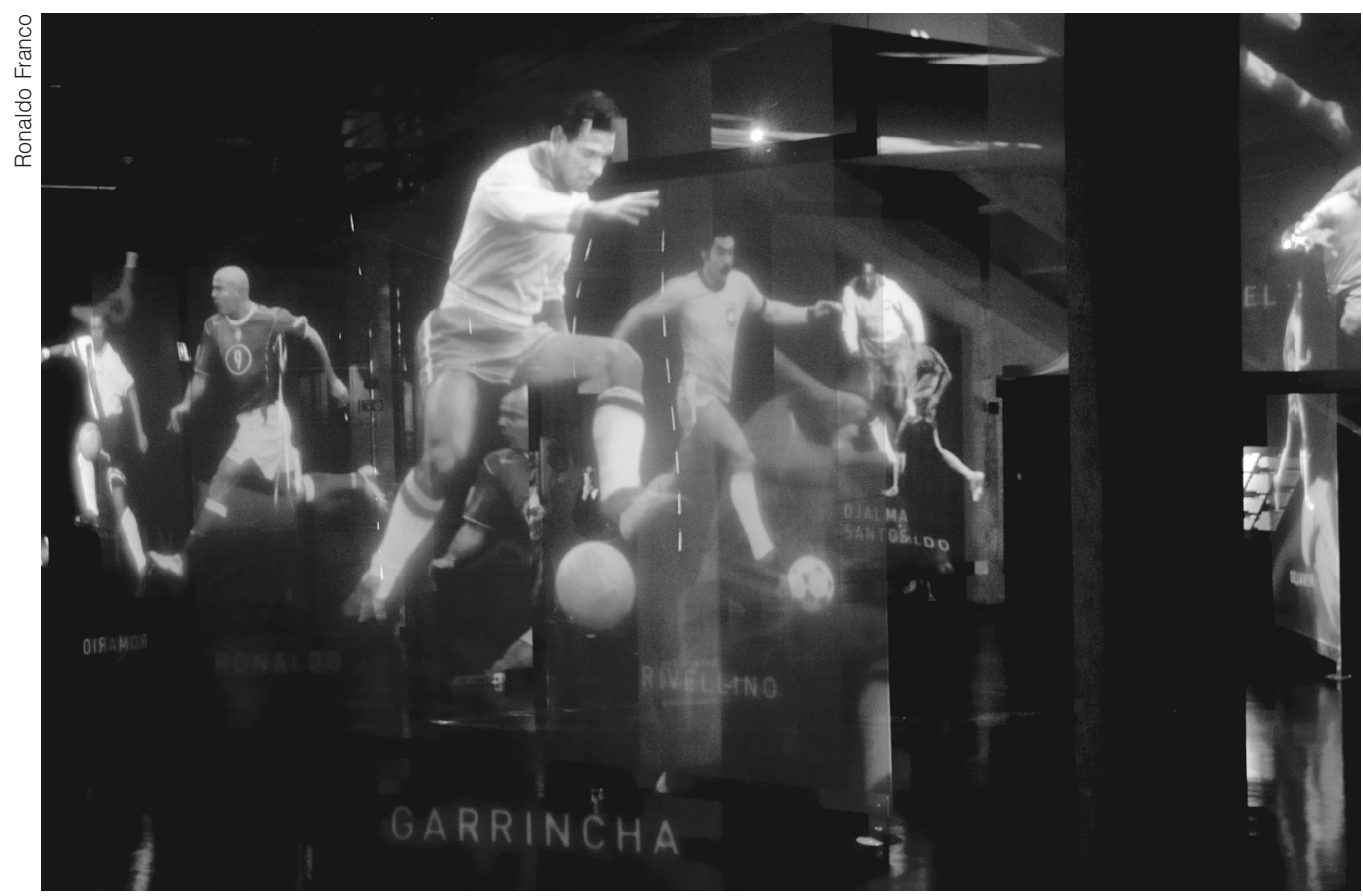

Na Sala dos Anjos Barrocos, as imagens de 25 craques brasileiros de todos os tempos, entre eles Pelé, Newton Santos, Garrincha, Didi, são projetadas em telas transparentes e suspensas no ar, flutuando diante dos olhos. 
O projeto arquitetônico é de Mauro Munhoz e curadoria do jornalista Leonel Kaz. A diretora de cinema e cenógrafa Daniela Thomas e o arquiteto Felipe Tassara são os responsáveis pela museografia. A direção de arte do Museu está sob a responsabilidade do designer Jair de Souza. O time conta, ainda, com uma equipe de consultores liderada pelo jornalista João Máximo, que inclui os jornalistas Celso Unzelte e Marcelo Duarte.

\section{A ARQUITETURA}

O partido da arquitetura é revelar as estruturas do Estádio do Pacaembu, seu avesso, seus interiores. $\mathrm{O}$ arquiteto Mauro Munhoz, responsável pelo projeto do Museu, optou por uma caracterização urbana, com o objetivo de manter a estética original do estádio. Por isso, cada sala deixa aparente a estrutura de concreto do prédio. Ele propõe também um novo uso da praça Charles Miller, que antes era basicamente frequentada por torcedores e agora terá um público diferente: visitantes do Museu, das mais variadas idades, que vão poder permanecer no local e usufruir dele.

No térreo, estão localizados o auditório Armando Nogueira, a Sala de Exposições Temporárias Osmar Santos, o bar-café O Torcedor e a loja de souvenirs do Museu. Durante as obras, lajes foram retiradas para criar um pé-direito

triplo na entrada (o hall de acolhimento, chamado de Grande Área), o que permite ao visitante uma melhor compreensão do espaço e de sua arquitetura. Uma passarela de vidro, no segundo andar, oferece a bela vista da praça e, durante a visita, é possível ver o estádio com suas arquibancadas e gramado.

\section{O CONTEÚDO}

O Museu do Futebol é típico do terceiro milênio: propõe uma narrativa linear, obtida com o uso de multimeios. A história do futebol é contada com base nos eixos de emoção, história e diversão. A curadoria de Leonel Kaz revela uma sequência de experiências visuais e sonoras que relacionam o esporte e a vida brasileira no século XX. Para se ter uma ideia da quantidade de vídeos exibidos no Museu, são seis horas de imagens.

\section{A MUSEOGRAFIA}

Trazer o conceito do mobiliário urbano, simples, rústico e prático para dentro do Museu é a proposta de Daniela Thomas e Felipe Tassara. "Trouxemos para as paredes do Estádio do Pacaembu a ideia de passageiro e precário das ruas. Assim, o projeto aproveita a 'precariedade' arquitetônica do prédio", explica Daniela Thomas.

As paredes são feitas de materiais brutos, como ferro, metais, aços, madeiras - como os que sustentam a estrutura de um edifício em construção e 
comunicação \& educação • Ano XIV • Número 3 • set/dez 2009

depois são descartados. Aqui, contudo, elas dão sentido ao conteúdo das salas e existem para fixar as realidades vividas durante o século do futebol no Brasil.

Logo na entrada, um auditório com 180 lugares está preparado para receber grupos escolares, ou mesmo sediar eventos e mostras de filmes. O Museu do Futebol também respeita e aplica as normas de acessibilidade para garantir a visita de todos. Além das obras de criação do Museu, as fachadas do estádio já foram restauradas e têm nova iluminação.

\section{OS TRÊS EIXOS DO MUSEU: EMOÇÃO, HISTÓRIA E DIVERSÃO}

\section{Emoção}

Esse eixo trata do futebol a partir da emoção que ele desperta nas pessoas.

Grande Área: nesse grande hall de entrada está a primeira instalação artística do Museu. Idealizado por Daniela Thomaz e Felipe Tassara, o espaço traz um grande painel fotográfico, que reúne imagens ampliadas dos mais variados objetos, símbolos da paixão pelo futebol. São canecas, flâmulas, chaveiros e cinzeiros, entre outros. Ao sair da Grande Área, o ídolo Pelé dá as boas-vindas aos visitantes em um filme exibido em português, inglês e espanhol.

Pé na Bola: são imagens que mostram como o futebol nasce em todos os lugares, todos os dias, em todos os terrenos, com todos os tipos de calçado. Telas em sequência exibem imagens de crianças chutando bolas improvisadas - de meias, barbante, plástico -, em campos de várzea e areia. É o futebol do dia a dia do povo brasileiro. As imagens da bola nas telas formam uma seta que indica a entrada para o visitante. Com isso, transmite-se também a ideia de que, naquele instante em que as imagens estão sendo vistas, a bola está sempre rolando em algum lugar no Brasil.

Sala dos Anjos Barrocos: é entre essas crianças brasileiras que jogam o futebol improvisado, mostrado no Pé na Bola, que surge, na Sala dos Anjos Barrocos, um deus do futebol. Na entrada, imagens de 25 craques brasileiros de todos os tempos, entre eles Pelé, Newton Santos, Garrincha, Didi, Romário, Ronaldo, Sócrates e Rivelino, são exibidas em tamanho natural. Como essas imagens são projetadas em telas transparentes suspensas no ar, tem-se a ilusão de que os jogadores estão flutuando diante dos olhos.

Sala dos Gols: como um gol mexe com o torcedor? Apesar de durar um instante, o gol é eternizado na vida das pessoas. Na Sala dos Gols, personalidades narram gols que marcaram suas vidas, a história do País e a história do futebol. Nas telas são exibidos vídeos dos gols e depoimentos de Armando Nogueira, Daniel Piza, João Máximo, Fernando Calazans, Sérgio Noronha, Galvão Bueno, Juca Kfouri, Arnaldo César Coelho e Ruy Castro, entre outras personalidades.

Sala dos Rádios: no Brasil, o rádio nasce com o futebol. E quando não há imagem, são os grandes narradores que tornam os gols inesquecíveis no ima- 
ginário das pessoas. Nessa sala é possível ouvir consagradas narrações feitas por Ary Barroso, Fiori Gigliotti, Oduvaldo Cozzi, Waldir Amaral, Jorge Cury e Osmar Santos, entre outros.

Sala da Exaltação: uma sala escura é invadida pela vibração, pelo colorido e pela criatividade das torcidas. Com o som ensurdecedor de hinos, gritos e canções, o visitante termina a primeira parte do percurso experimentando toda a euforia existente nos momentos de uma partida de futebol. Em um grande vão livre, na passagem do primeiro para o segundo andar, são projetadas - entre vigas e pilares de sustentação da arquibancada - imagens de exaltação ao futebol, fazendo renascer a emoção dos torcedores. Ao fundo, a visão inédita de terra, concreto, areia e pedras, materiais utilizados na época da construção do Estádio do Pacaembu.

\section{História}

Depois de vivenciar toda a emoção que envolve o futebol, a narrativa do eixo história conta a origem e a evolução do esporte e acompanha a trajetória do próprio País.

Sala das Origens: o esporte surge no Brasil trazido pelo inglês Charles Miller, no final do século XIX. A Sala das Origens mostra esse momento inicial até a profissionalização do esporte e a popularização dos clubes. O espaço lembra um museu tradicional, com 431 fotos raras emolduradas e um vídeo que contam a história do futebol e do País. Presta-se ainda uma justa homenagem aos ídolos: Friedenreich, filho de mãe brasileira negra e pai alemão branco, com papel fundamental na disseminação do esporte no Brasil; e Marcos Carneiro de Mendonça, primeiro goleiro oficial da seleção brasileira e símbolo do futebol aristocrático, que depois se popularizou.

Sala dos Heróis: aqui, vemos imagens de pessoas que ajudaram a construir a identidade brasileira: Villa-Lobos, Carlos Drummond de Andrade, Oscar Niemeyer, Mário de Andrade, Noel Rosa, Cândido Portinari, Jorge Amado e Mário de Andrade estão lado a lado com Leônidas da Silva e Domingos da Guia, mostrando como os ídolos do futebol começariam a ganhar importância. O futebol se transforma em um instrumento de afirmação nacional em plenos anos 1920-1930, quando a força do rádio disseminava a arte, a música e a política.

Rito de Passagem, a Copa de 1950: chega o momento em que o Brasil vai apresentar seu futebol para o mundo. A seleção precisa apenas de um empate, porém é derrotada pelo Uruguai, no recém-inaugurado Estádio do Maracanã, o maior do mundo. Aqui, no Rito de Passagem, a ideia é fazer o visitante reviver o impacto dessa derrota. Dentro de um túnel fechado, ouve-se um texto narrado por Arnaldo Antunes, que descreve os momentos que precederam a partida. Em seguida, após o fim do jogo, as imagens continuam passando, porém o silêncio dentro da sala é total, experimentando-se o mesmo silêncio que "calou" o País naquele momento. 


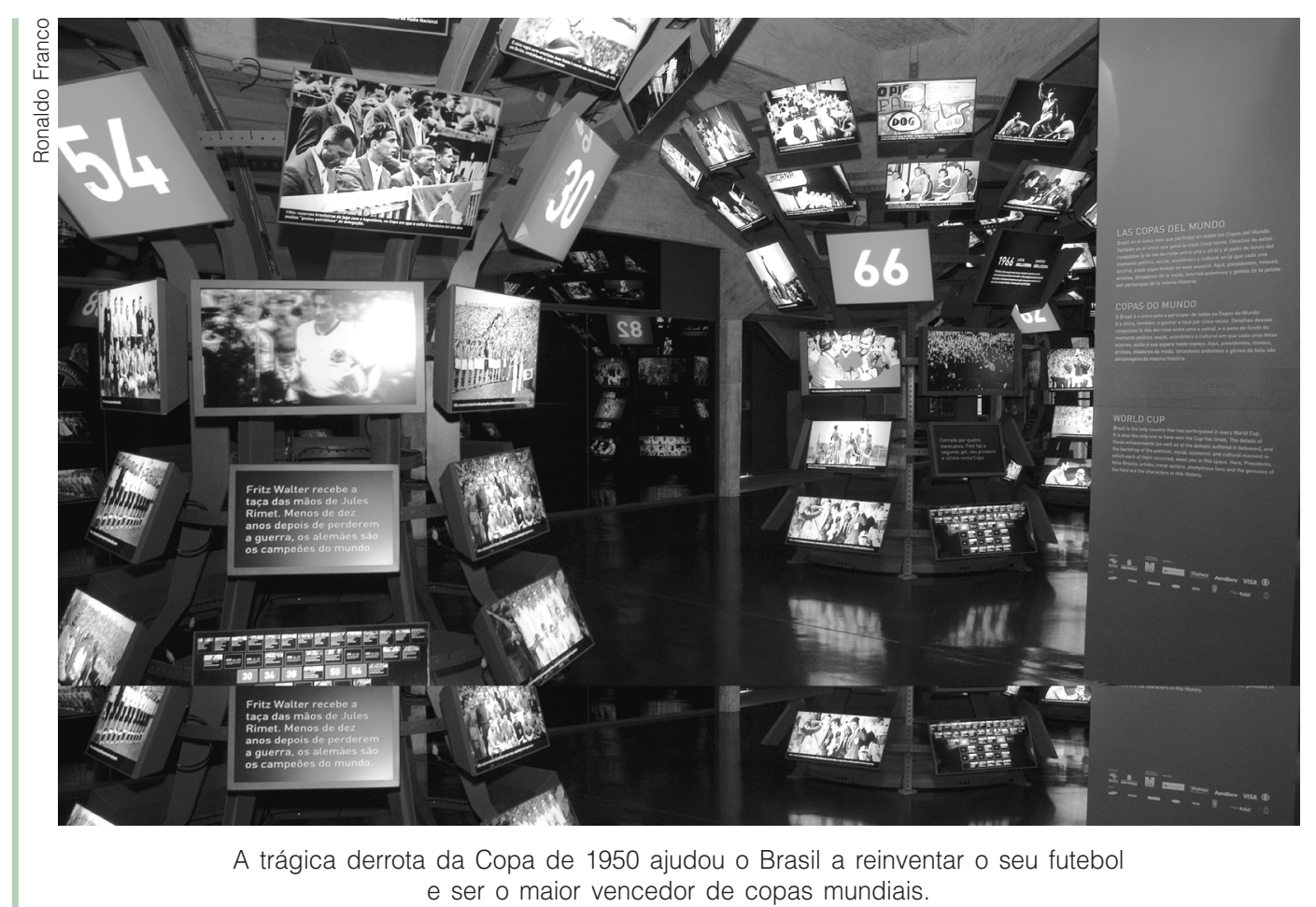

Sala das Copas do Mundo: a derrota da Copa de 1950 para o Uruguai foi uma tragédia que serviu de lição para o Brasil, que, junto com seu futebol, se reinventou, dando início a um grande período de triunfos. Nesta sala vemos a evolução do País e da seleção brasileira. São vídeos que mostram como o futebol acompanhou e ainda acompanha a evolução da cultura e dos costumes da sociedade. As imagens revelam a moda, a música, a política e as transformações sociais de cada época.

Experiência Pelé e Garrincha: são filmes que evidenciam a genialidade desses craques brasileiros, Pelé e Garrincha. A sala exibe filmes de cinco minutos cada, que demonstram a atuação deles em campo. Vale destacar que os dois grandes ídolos nunca perderam uma partida juntos.

\section{Diversão}

Depois de passear pela emoção e pela história do futebol, o visitante agora entra no terceiro eixo do Museu: a diversão. Em destaque, o futebol como jogo, como brincadeira, como rivalidade entre torcidas, como atividade lúdica.

Sala dos Números e Curiosidades: placas seguem a linguagem de um grande almanaque, propondo um trajeto de números, táticas, datas, histórias, superstições. No mesmo espaço, três mesas de pebolim/totó, com bonecos posicionados em diversos esquemas táticos, divertem o público.

Sala da Dança do Futebol: dentro de bolas de futebol gigantes, convidados especiais narram crônicas literárias de temas ligados ao esporte: Marcelo Duarte fala sobre o "drible"; Celso Unzelte, sobre o "gol"; João Máximo, sobre o 
"goleiro"; e Juca Kfouri, sobre o passado e o presente do futebol por meio de imagens do "Canal 100".

Jogo de Corpo: é a ciência no futebol. De volta ao primeiro andar, o visitante é apresentado a várias atividades interativas, com destaque para um filme em 3D no qual um famoso jogador é o protagonista. O filme mostra como o corpo do atleta se comporta durante o jogo. Vemos primeiro só o esqueleto e os músculos, e aos poucos a imagem vai revelando o craque. Nessa sala, é possível ainda que o visitante teste a potência do seu chute; assista a jogadas em câmera lenta; simule a cobrança de um pênalti; brinque com jogos; e encontre os dados de seu time em um hall de painéis com os 128 times de futebol que já participaram, ao menos uma vez, do campeonato brasileiro.

Sala Pacaembu: última parada do percurso, este é o espaço dedicado ao Estádio do Pacaembu. A proposta é celebrar o patrimônio histórico e explicar a história de um dos estádios mais antigos do País. Contém imagens, por exemplo, da construção do estádio.

O Museu do Futebol apresenta, ainda, outros espaços que interligam suas várias salas. No meio do percurso, uma passarela de vidro conecta duas alas do Museu: ala Leste e ala Oeste. Suspensa por tirantes, ela parece flutuar atrás do pórtico monumental do Estádio do Pacaembu. Este é um espaço para uma pausa, com bela vista da Praça Charles Miller. Como é uma passarela de vidro, o fluxo de pessoas também é visível para quem está do lado de fora do Museu. Além disso, ao sair da Sala dos Números e Curiosidades, o visitante tem a possibilidade de realizar uma visita à arquibancada e ver o campo.

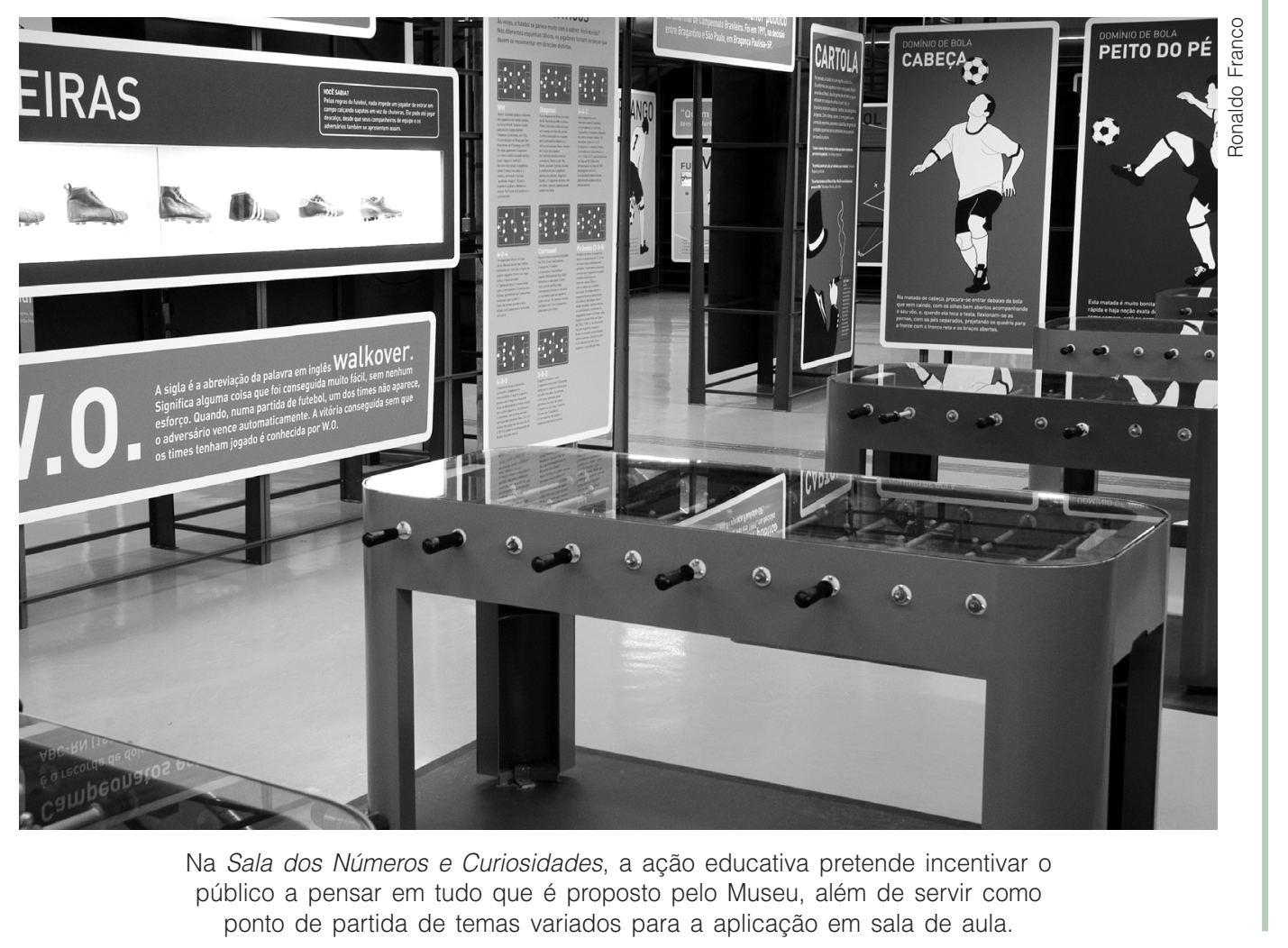


comunicação \& educação • Ano XIV • Número 3 • set/dez 2009

O Museu do Futebol promete atrair não apenas os torcedores e a população de São Paulo, mas também uma parcela dos dois milhões de pessoas que vão à cidade a trabalho. $\mathrm{O}$ foco está voltado para a criação de uma infraestrutura museológica e de ação educativa que incentive o público a pensar em tudo que é proposto, além de servir como ponto de partida de temas variados para a aplicação em sala de aula.

\section{Serviço}

Museu do Futebol

Praça Charles Miller, s/n, Estádio do Pacaembu - São Paulo/SP - Brasil Aberto de terça a domingo, com entrada das $10 \mathrm{~h}$ às $17 \mathrm{~h}$ e permanência no museu até as $18 \mathrm{~h}$ (sujeito a alterações em dias de jogos vespertinos no Estádio do Pacaembu. Consulte sempre a agenda antes de programar a visita).

Ingressos: $\mathrm{R} \$ 6,00$. Estudantes com carteirinha, aposentados e maiores de 60 anos: R\$ 3,00 - mediante comprovação.

Público não pagante: crianças até 7 anos, professores da rede pública e estudantes de escolas públicas municipais e estaduais, mediante visitas agendadas. Visitação gratuita às quintas-feiras, mediante a retirada de ingresso na bilheteria. Telefone: (55) 11 3664-3848 